\title{
PROPRIEDADE E DIREITO ENTRE OS MUÇULMANOS DE PORTUGAL: DOS BENS COMUNS À GESTÃO DO PATRIMÓNIO DO REI
}

\author{
Maria Filomena Lopes de Barros*
}

A propriedade detida ou usufruída pelos muçulmanos do reino português revela características específicas, advindas de uma mescla entre formas de exploração que se impõem no contexto da medievalidade ocidental, como de uma individualidade imputável aos seus traços identitários, emanando do próprio direito islâmico. Vector que, de resto, não surpreende na avaliação global de uma identidade mudéjar, justamente singularizada pela sua dupla adscrição à cultura maioritária, assim como aos valores matriciais que definem a sua etnicidade e consequente alteridade como grupo diferenciado.

Dualidade que define uma identidade e um ethos, necessariamente distinta de outras dimensões políticas muçulmanas, configurando o mudéjar do discurso historiográfico, de cuja sujeição aos poderes cristãos não está ausente a sua própria participação nesses mesmos mecanismos de poder. Aspecto bastas vezes preterido em função de uma perspectiva demasiado estática dos processos sociais e de uma noção abstracta de poder. O programa político dos reinos medievais cristãos, necessariamente definido e controlado pelas suas elites, recupera um Islão domado ${ }^{1}$, isto é, submetido aos seus próprios interesses, através de actos escritos de legitimação.

Esta remição para a praxis política de comunidades muçulmanas, administrativamente estruturadas e dispondo de autoridades próprias, pressupõe um ininterrupto diálogo (ainda que necessariamente assimétrico), que fluirá entre os dois extremos da escala política, numa assumpção do monarca como

* Universidade de Évora / CIDEHUS.

1. A ideia de "domesticação" enforma a raiz árabe dağana, de que deriva o particípio mudağğan, "mudéjar", F. DE LA GRANJA, «El problema del mudejarismo en la lengua y en la literatura», Qurtuba, 3, 1998, pp. 184-194; J.-P. MolÉNAT, «Communautés musulmanes de Castille et du Portugal. Le cas de Tolède et de Lisbonne», en Expansion occidentale (XIe-Xve siécles). Formes et conséquences. XXXIIIe Congrès de la S.H.M.E.S, Madrid, Casa de Velásquez, 23-26 mai 2002), Paris, Sorbonne, 2003, p. 206. 
o "natural" protector dos "seus" muçulmanos. Estes, de resto, no reino português, constituir-se-ão como os agentes sociais mais activos na definição dos parâmetros da sua sujeição, através do seu próprio capital cultural e simbólico, num processo de redefinição constante, adaptado e solicitado pela natural evolução social e política da medievalidade.

\section{DIREITO ISLÂMICO, PRODUÇÃO VERNÁCULA}

O direito islâmico constituir-se-á como um dos vectores estruturantes tanto de identidade como de sujeição, aspectos complementares de um mesmo processo. Se, num período formativa, ele enformará necessariamente as condições de permanência das diferentes comunidades muçulmanas peninsulares (correspondendo a uma natural premência dos conquistadores), a sua evolução não deixa de se fazer sentir ao longo das diferentes centúrias, em função dos distintos contextos considerados.

Em finais do séc. XIV e ao longo do XV, é o monarca português que, ao reivindicar a sistematização das cláusulas sobre as heranças dos muçulmanos, estabelece uma apropriação lidimada no próprio direito sucessório islâmico ('ilm al-farā'id), concitando a produção de textos legais neste sentido. Acção que se estrutura num discurso de legitimação, porque implica um registo de paralelismo com os dirigentes muçulmanos (os pretéritos, mas também os coevos de Terra de Mouros), canalizando para o soberano, os bens que, por falta de herdeiros, seriam dirigidos para o erário público (bayt al-māl). De resto, esta perspectiva será expressamente enunciada no prólogo do segundo texto, que se inicia justamente pela justificação ideológica da medida: "Porque a herança dos Mouros forros moradores em estes Regnos, e Senhorios pertencem a Nós [Rei] em muitos casos, assy como he devuda aos Reys Mouros em seus Regnos, e Senhorio (...)"2.

Neste sentido, os dois textos elaborados, em português, sobre esta problemática pelos letrados da comuna de Lisboa deixam claro a prioridade subjacente à sua própria produção. O prólogo do mais pretérito, do reinado de D. João I (1385-1433), refere que o levantamento se constitui como uma resposta à pergunta feita pelo juiz Álvaro Peres, pelo qual o soberano ordenou que se soubesse de que modo ele próprio se constituía como herdeiro dos bens dos muçulmanos $^{3}$. O segundo, de D. Afonso V (1438-1481), justifica-se em função do soberano

2. M. De Albuquerque (ed.), Ordenações Afonsinas, Lisboa, Fundação Calouste Gulbenkian, 1984, Livro 2, tit. XXVIII, p. 222.

3. Deste diploma existem dois treslados: Torre do Tombo (T.T.), Inquirições de D. Afonso III, livro 4, fls. 14 v.-15 v; Idem, Gaveta 10, maço 12, doc. 17, fls. 9 v.-13. Um resumo do diploma encontrase em M. ${ }^{a}$ L. MARTins, Subsídios para o estudo dos Judeus e dos Mouros nos reinados de D. João I e de D. Duarte, Dissertação de Licenciatura apresentada à Faculdade de Letras da Universidade de Lisboa, Lisboa, 1961, pp. 146-147. 
considerar a produção anterior pouco legível ("imperfeita, e muito escura"), o que teria dado origem a "muitos debates, e contendas (...) antre elle e os ditos Mouros". Para superar essa situação, o monarca incumbiu ao alcaide da comuna de Lisboa a tarefa de juntar "mouros letrados e sabedores em sua lei", para a corrigir e acrescentar no que necessário fosse. O resultado final será o publicado nas Ordenações Gerais do Reino, com o título significativo "De como El Rey deve herdar os Mouros forrros moradores em seus Regnos, e Senhorio" ${ }^{4}$, num diploma de uma maior abrangência e complexidade, denotando um total domínio da casuística sunnita malikita.

Do mesmo modo, se estrutura a sistematização da tributação dos muçulmanos, coetânea do primeiro diploma, validada e subscrita (de resto, como assinante único), pelo tabelião da comuna de Lisboa, Jufez, ou, como consta da sua assinatura em árabe Yūsuf b. Ibrahīm b. Yūsuf al-Lahmī. Uma vez mais, a relação directa entre esta produção e o monarca se especifica no prólogo do diploma: "Esta he a declaraçom dos foraes dos moros de como devem de pagar hos derreitos a ell Rey per eses foraes antygamente e per derreitos dos mouros e per costume de que ell rey antygamente esta pose delles per esta gisa hos mouros e as mouras pagarem a ell Rey seus derreitos..." ${ }^{5}$. O direito islâmico estrutura esta sistematização, na continuidade do que se verifica desde a outorga dos primevos forais, num desenvolvimento e adaptação dos juristas de Lisboa às realidades concretas do reino ${ }^{6}$.

As prioridades do soberano (como do exercício de qualquer poder maioritário) condicionam os parâmetros identitários das minorias, materializando cabalmente a assimetria do exercício de poder presente neste tipo de relações. No entanto, dessa manipulação depreende-se a imanência do direito islâmico enquanto estruturador destas comunidades ou, pelo menos, das suas elites. Este capital cultural marca, de resto, uma produção peninsular noutras línguas vernáculas. Em catalão, refira-se o Llibre de la Çuna e Xara, datada de 3 de Março de 1408, que sobreviveu através de uma cópia, realizada aproximadamente entre 1460 e 14857. Em castelhano, a Suma de los principales mandamientos y devedamientos de la Ley y Çunna ou Breviario Sunni, datado de 1462 e que se deve ao muftí e alfaquí da aljama de Segóvia, Isā ibn Gābir (ou, em romance, Iça Jedih, Gebir ou Gidelli) ${ }^{8}$ ou as designadas Leyes de Moros $^{9}$. Esta última

4. M. De Albuquerque (ed.), Ordenações Afonsinas, Livro 2, tit. XXVIII, pp. 222-242.

5. Portugalia Monumenta Historica. Leges et Consuetidinis, Lisboa, Real Academia da História, 1856, pp. 98-100.

6. M M. F. BArros, Tempos e Espaços de Mouros. A Minoria Muçulmana no Reino Português (Séculos XII $a X V)$, Lisboa, Fundação Calouste Gulbenkian / Fundação para a Ciência e a Tecnologia, 2007, pp. 393-404; Idem, «Direito islâmico no Reino Português», en F. Toro y J. RodRíGUEZ, VII Estudios de Frontera, Islam y Cristiandad. Siglos XII-XVI, Jaén, Diputación de Jaén, 2009, pp. 461-471.

7. C. BARCeló (ed.), Un tratado catalán medieval de derecho islâmico: El LLibre de la Çuna e Xara dels Moros, Córdova, Universidad de Córdova, 1989.

8. Segundo a proposta de G. WIEGERS, Islamic Literature in Spanish and Aljamiado. Yça of Segovia. His antecedents and sucessors, Leiden, Brill, 1994.

9. Ambos publicados por P. DE GAYAngos, Memorial Historico Espanõl, V, 1853. 
obra, resultado de uma tradução (se bem que parcial, fragmentada e abreviada), do tratado jurídico Kitāb Al-Tafrī , de Ibn Al-Ǧallāb (m. 988), largamente difundido entre os mudéjares e, posteriormente, os mouriscos peninsulares ${ }^{10}$, comprova cabalmente a continuidade de uma matriz árabe dominada pelos especialistas muçulmanos de figh ao longo da medievalidade. Aspecto corroborado por outros elementos documentais. Uma obra de Ibn al-Ğazarī alDimašqi (1350-1429), escrita na Síria em finais do séc. XIV, será traduzida em Aragão, em romance aljamiado, provavelmente na primeira metade do $\mathrm{XV}^{11}$. Por outro lado, a biblioteca de um "alfaquí" de Ocaña (de finais da centúria quatrocentista), constituída tanto por manuscritos em árabe, como em romance, em aljamiado e, mesmo, bilingues, revela cabalmente as diferentes adscrições culturais e consequentemente linguísticas, destas comunidades de fronteira ${ }^{12}$.

Mais problemática se constitui a questão da formação dos agentes sociais que dominam e aplicam o direito islâmico. Em diferentes registos ela se poderá, contudo, perspectivar. Por uma parte, nas relações com o território do dār al-Islām, numa direcção biunívoca, implicando quer a saída de muçulmanos peninsulares para concretizar os seus estudos ${ }^{13}$, quer a passagem ou fixação de forâneos pelo território peninsular. A conquista de Ceuta pelos portugueses, em 1415, potencializa, paradoxalmente, os contactos entre os muçulmanos de um e de outro lado do Estreito, que, de resto, concorrem num

10. Ver, por exemplo, S. Abboud-Haggar, "Las Leyes de Moros son el libro de Al-Tafrī », Cuadernos de Historia del Derecho, 4, 1997, pp. 163-201; Idem, El Tratado Jurídico de Al-Tafrí Ibn Al-Ğallāb. Manuscrito aljamiado de Almonacid de la Sierra, 2 vols., Zaragoza, Institución "Fernando El Católico", 1999.

11. S. AbBoud-HaGgAR, «'Udattu l-ḥiṣni l-hasīn de Ibn al-Ğazarī al-Dimašqī. Una muestra de la transmission de los asuntos religiosos islámicos de Oriente al Occidente mudéjar en el XV», Anaquel de Estudios Árabes, 16, 2006, pp. 5-63.

12. Neste caso concreto, contudo, estando presentes temáticas tão variadas como a religião, a medicina, a farmacopeia, a moral ou a astrologia, não se registam quaisquer manuscritos directamente relacionados com o direito. A datação do documento mais recente desta biblioteca é de 1500. J. Albarracín, "Actividades de un faquih mudéjar», en VI Simpósio Internacional de Mudejarismo. Actas, Teruel, Centro de Estudios Mudéjares, 1995, pp. 437-444. O termo "alfaquí" deve, portanto, designar mais um cargo administrativo do que propriamente um especialista de figh. Diferentemente se apresenta outro caso, o do alfaquí Muhammad b. 'Alī al-Ğayyār al-Anșārī, imām da mesquita de Cútar, do território de Comares, de finais do séc. XV. De facto, nos seus três livros "de ofício", em árabe, entre uma miscelânea de temáticas, avultam os aspectos jurídicos, quer através de formulários notariais, quer de treslados de obras de jurisconsultos, nomeadamente da Muwatțà de Mālik. Trata-se, no entanto, de um neo-mudéjar, no sentido em que essa alcaçaria foi apenas incorporada no domínio cristão em 1487. M. ${ }^{a}$ CALERO SECALL, «Los manuscritos árabes de Málaga: los libros de un alfaquí de Cútar del siglo XV», en M. J. VIGUERA y C. CASTillo (eds.), Los Manuscritos Árabes en España y Marruecos. Homenaje de Granada y Fez a Ibn Jaldún, Granada, Junta de Andalucía-Fundación El Legado Andalusí, 2006, pp. 151-174.

13. É o caso de Abdurramen Madçor morador de Valência, que é referenciado, em 1434, numa viagem de Almeria para Tlemcén, com o objectivo de "aprender e studiar", R. SALICRÚ I LLUCH, Documents per a la Història de Granada del regnat d'Alfons el Magnànim (1416-1458), Barcelona, CSIC, 1999, doc. 284, pp. 337-338. 
universo legal comum, o do malikismo ${ }^{14}$. Embora não seja referida especificamente a vertente dos especialistas de direito, a participação de notáveis norteafricanos em actos judiciais parece comprovar esta tendência ${ }^{15}$.

Ambos os aspectos não se mostram incompatíveis, mas antes complementares de uma vertente interna de formação que, para a comuna de Lisboa, se deveria concretizar na escola dos mouros, edifício contíguo à mesquita grande ${ }^{16}$. De facto, é da comuna desta cidade que, desde a conquista do território, avulta a produção do direito islâmico em íntima conexão com o poder monárquico, como os diplomas supra-mencionados o testemunham. A definição tributária, a partir do labor desses juristas, constituir-se-á, a partir de finais do séc. $\mathrm{XIV}$, como o modelo a aplicar a todas as comunas muçulmanas do Reino, numa uniformidade do foro de Lisboa enquanto apreensão tributária e fiscal inteiramente subordinada à Coroa ${ }^{17}$.

\section{SUNNA E ESPAÇO: DO PATRIMÓNIO HUBS AOS BENS AL-MUSLIMİN}

Este aproveitamento do direito islâmico projecta-se, contudo, para lá do seu imediato interesse na concretização dos objectivos de rentabilização por parte da Coroa, participando de própria imanência identitária e vivencial mudéjar. Vector menos visível, porque obnubilado por uma assimetria documental, estruturada num Arquivo e numa memória nacionais, estigmatizados pela expulsão das minorias étnico religiosas peninsulares. $\mathrm{O}$ acervo documental constitui-se,

14. A influência da escola malikita entra em retrocesso no séc. X, limitando-se a sua continuidade ao Ocidente, durante todo o período medievo, S. ABBOUD-HAGGAR, «Las Leyes de Moros son el libro de $A l$-Tafrī $\gg$, p. 171.

15. Em 1488, um pleito que opunha dois muçulmanos pela escrivaninha da comuna de Loulé (Algarve), será arbitrado por um grupo de notáveis da comuna de Lisboa conjuntamente com um "cavaleiro da casa de Azamor", designado como "Acaide Alfacim", "Caide Alfaquim" ou "Çaide Alfaim". O primeiro termo pode traduzir, em árabe, ou o nome próprio Saìd ou o título de "Dom", devendo, o segundo, reflectir, a sua condição, transitória ou permanente, de juiz (hākim). M. ${ }^{\mathrm{a}} \mathrm{F}$. Barros, Tempos e Espaços de Mouros. A Minoria Muçulmana no Reino Português (Séculos XII a XV), Lisboa, Fundação Calouste Gulbenkian / Fundação para a Ciência e a Tecnologia, 2007, pp. 337-339.

16. Para a descrição do edifício ver: L.F. OliveIRA e M. VIANA, «A Mouraria de Lisboa no século XV», Arqueologia Medieval, 2, 1993, p. 199. É significativa a existência de uma escola (madraṣa) enquanto equipamento colectivo distinto da própria mesquita, o que poderá apontar, de facto, para uma formação mais especializada do que o simples ensino do Corão às crianças muçulmanas. Confronte-se, por exemplo, esta realidade com a da mesquita de Sevilha, em que um acto notarial de 1502, com o levantamento dos respectivos bens, menciona 13 tábuas para ensinar as crianças, remetendo essa prática para o interior do mesmo edifício, J. HiNojosA Montalvo, Los mudéjares. La voz del Islam en la Espanã cristiana, vol. I, Teruel, Centro de Estudios Mudéjares, 2002, p. 167.

17. M. M. F. BArros, Tempos e Espaços de Mouros..., pp. 393-404. 
pois, como um elemento de exterioridade face às comunidades consideradas, cujos arquivos próprios entretanto desapareceram, se não considerados como ideologicamente perturbadores, pelo menos como conspicuamente dispensáveis. Apenas alguns elementos dispersos emergem, pois, enquanto testemunho indirecto da vivência comunitária mudéjar e da materialização do seu direito próprio. As formas de apropriação e de rentabilização da propriedade testemunham, em alguns casos, essa vivência colectiva, com base nos princípios da sunna. Um desses vectores respeita à dominância dos bens colectivos, complementares da propriedade privada, consubstanciando uma coesão sócio-espacial, geradora de laços de solidariedade entre o grupo. Princípio geral que se materializa em dois diferentes aspectos da realidade do Reino português.

Uma primeira categorias recai sobre os bens referidos como "da mesquita", detectados apenas em Lisboa e, numa breve alusão, de 1506, para Santarém. Neste último caso, é somente mencionado um olival, em Vale de Estacas, que havia sido da "mesquita dos mouros"18, sendo bastante mais completas as referências às propriedades dos dois locais de culto da comuna lisboeta.

De facto, a colonização cristã da mouraria da cidade, nos últimos anos do séc. XV e nos primeiros do XVI, contribui, paradoxalmente, para o conhecimento do que fora a zona de vivência muçulmana. O édito de expulsão/assimilação das duas minorias religiosas, publicado em Dezembro de 1496 pelo rei D. Manuel $\mathrm{I}^{19}$, leva a uma apreensão desses espaços, por parte do soberano, os quais serão, posteriormente, objecto de doação ao Hospital de Todos-osSantos. Os contratos celebrados com os novos enfiteutas permitem, por um lado, acompanhar o processo de emigração efectiva de parte da população muçulmana e, por outro, desenhar uma geografia do bairro, em função das pormenorizadas referências materiais aí exaradas. O crescimento populacional do que era a principal cidade do Reino, encontra, pois, uma nova e conveniente área de fixação, num espaço imediatamente contígua à muralha, no seguimento da Porta de S. Vicente e do caminho que levava ao interior agrícola ${ }^{20}$.

É esta nova conjuntura que permite vislumbrar a realidade do que foram alguns dos aspectos da vivência sócio-espacial da comunidade muçulmana da cidade, em função dos bens das respectivas mesquitas. A mesquita pequena, sita num dos extremos do bairro, deverá corresponder à denominação de mes-

18. Arquivo da Misericórdia de Santarém, Livro $1^{\circ}$ de Palhais, fl. 11.

19. Apenas a $3^{a}$ edição das Ordenações Manuelinas (Jacobo Cronberguer, Lisboa, 1521) contempla a expulsão dos mouros, omissa no texto das anteriores, que mencionam apenas os judeus. No entanto, os tempos de saída do Reino são comuns às duas minorias, pelo que se opta por considerar esta data, de resto a oficialmente consagrada para este evento. Sobre os problemas de datação ver: F. SOYER, The Persecution of The Jews and Muslims of Portugal. King Manuel I and the End of Religious Tolerance (1496-1497), Leiden-Boston, Brill, 2007, pp. 259-260.

20. Sobre a mouraria da cidade ver: L.F. OliveIRA e M. VIANA, «A Mouraria de Lisboa no século XV», Arqueologia Medieval, 2, 1993, pp. 191-209. 
quita de Bebe Iça (Bāb Isà $)^{21}$, exactamente por se encontrar junto de uma porta $(b \bar{a} b)$ da mouraria, em contraponto à mesquita aljama, designada pela documentação como mesquita grande. A primeira possuiria pelo menos cinco tendas, a ela contíguas ${ }^{22}$, sendo, provavelmente da segunda, um conjunto de propriedades descritas, apenas, como da mesquita dos mouros, que consistiam em três courelas de olival, na Panasqueira, plantadas com 127 oliveiras, entre grandes e pequenas, mencionadas apenas como tendo pertencido à mesquita dos mouros (1499-VI-12) ${ }^{23}$, uma casa contígua ao espaço de culto central (1498-IV-4) ${ }^{24}$, e um chão no Arrabalde Novo (1504-I-6) ${ }^{25}$.

Embora a documentação seja omissa sobre a categorização jurídica desse património, ele deverá, contudo, corresponder aos bens waqf ou ḩubs ${ }^{26}$. Estes legados piedosos, definem-se em função de três vectores: constituírem-se como uma acção livre e voluntária, que integra os actos espontâneos de liberalidade do muçulmano (tabarruca ât), considerada pelo direito islâmico como uma acto recomendável (mandīb ou mustahabb); a sua finalidade ser, sempre, piedosa, conceptualizando-se como qurba (obra piedosa), o que implica que não contradiga os valores e princípios do Islão; o bem ḥubs ser inalterável e inalienável, não podendo ser destinado a uma finalidade distinta da estipulada pelo doador, nem objecto de venda, doação ou herança ${ }^{27}$.

Não existe, de resto, uma tipologia explícita das finalidades do hubs, embora ele não possa existir sem a especificação dos objectivos a que se destina. Em termos gerais, estes incidem sobre tudo o que seja susceptível de caber dentro do conceito corânico da acção realizada "por mor de Deus" (fì sabīl Allah"). O estudo de Alejandro García Sanjuán sobre Al-Andalus, englobando tanto a teoria como a prática jurídicas, contemplam uma abrangência dos âmbitos de aplicação destes legados, que o autor estrutura da seguinte forma:

21. T.T., Núcleo Antigo, 318, fl. 54 v.

22. Esse espaço de culto e as cinco tendas "que soíam de fazer foro à mesquita", são emprazadas pelo Hospital de Todos-os-Santos, em 1498-IV-4, a Jorge Gomes, que fora almoxarife em Sintra, e a sua mulher, Margarida Fernandes; T.T., Livro 2 de Estremadura, fls.106 v.-108.

23. S. Viterbo, «Ocorrências da vida mourisca», Arquivo Histórico Português, 5, 1907, pp. $91-93$.

24. Ibidem, p. 89.

25. T.T., Livro 9 da Estremadura, fls. 45 v. -47.

26. A terminologia oriental contempla o termo waqf face a hubs, que prevalece no Ocidente islâmico. Em castelhano medieval-moderno, o vocábulo aparece como habice, tal como se verifica nos Libros de habices de época cristã, redigidos em Granada em finais do século XV e inícios do XVI, quando se procedeu à repartição dos legados pios nazarís.

27. A. García SAnjuán, Hasta que Dios herede la Tierra. Los bienes habices en Al-Andalus (siglos X-XV), Huelva-Sevilha, Universidad de Huelva-Mergablum, 2002, pp. 21-22. Este carácter de perpetuidade implica ser preferível doar bens imóveis, por natureza imperecíveis, face à perdurabilidade dos bens móveis. Neste sentido, algumas doutrinas jurídicas pronunciam-se contra este última tipologia na formação de hubs, embora os malikitas se revelem mais flexíveis neste aspecto, já que reconhecem a temporalidade desses bens, admitindo, por isso, qualquer tipo de doação, A.M. CABALLEIRA, «Pauvreté et fondations pieuses dans la Grenade naṣride: aspects sociaux et juridiques», Arabica, 52, 2005, p. 399. 
mesquitas, finalidade bélica, cultural-educativa, assistencial (pobres e enfermos) e cemitérios ${ }^{28}$. Se bem que necessariamente estes pressupostos se tenham que subverter no contexto específico do mudejarismo (com a lógica exclusão do objectivo bélico), a referência a alguns destes aspectos marca, de facto, a legislação islâmica, em romance, produzida pelos muçulmanos portugueses.

Assim, na enunciação das cláusulas do direito sucessório, ao explicitaremse as condições em que o indivíduo pode dispor da terça dos seus bens, referese, a dada altura que a mesma pode ser deixada "a alguum servo ou serva, à Mesquita, ou a alguma Albergaria, ou casa de Oração, ou para refazimento de alguma Ponte, ou Fonte", ou ainda ser distribuída "por sua Alma em pobres, ou em cativos."29. O carácter público destas cláusulas demarca-se claramente das demais, que contemplam uma categorização dos indivíduos a quem a terça pode ser deixada ${ }^{30}$. Definir-se-iam, pois, as finalidades desses legados pios das comunidades portuguesas em função das instituições de culto e assistenciais, da manutenção dos bens materiais comunitários (expressos através da referências às pontes e fontes) e ainda na vertente assistencial dirigida aos pobres e ao resgate de cativos.

De facto, esta expressão da qurba, enquanto liberalidade do indivíduo muçulmano, complementa as obrigações internas colectivas da comunidade, que são descritas para Évora, em 1450, e para, Lisboa, em 1471. No primeiro caso, os pagamentos que impendiam aos muçulmanos abarcavam a manutenção dos muros que rodeavam o bairro, o estipêndio do carniceiro, o aluguer da respectiva carniçaria, e ainda as esteiras para a mesquita ${ }^{31}$. No segundo, refere-se o estipêndio do imām (capelão) e do porteiro da mouraria, as esteiras da mesquita, e a manutenção dos muros que rodeavam o bairro assim como dos seus arruamentos ${ }^{32}$.

Mais difícil será percepcionar de que modo se processava a gestão deste património, face ao silêncio documental de um arquivo cristão e, consequentemente, externo à comunidade. Em nenhum caso a problemática aflora a documentação, consignando-se igualmente um vazio, quando se definem as competências do escrivão das comunas ${ }^{33}$, o que poderá significar que estes bens da mesquita es-

28. A. García SANJUÁn, op. cit., p. 173. Para o Egipto mameluco, Adam Sabra categoriza os objectivos dos waqf em cuidados médicos (hospitais), educação (escolas), habitação, comida e água, enterro de pobres, morte e caridade (compreendendo, neste item, os complexos funerários que englobam diferentes instituições), A. SABRA, Poverty and Charity in Medieval Islam. Mamluk Egypt, 1250-1517, Cambridge, Cambridge University Press, 200, Capítulo 4 “Waqf", pp. 69-100.

29. M. De AlbuQuerQue (ed.), Ordenações Afonsinas, Livro 2, tit. XXVIII, p. 224.

30. De facto existem também doações em ḥubs familiares ou privados, ver A. GARCÍA SANJUÁN, op. cit., pp. 139-168; A.M. CABALLEIRA, Legados píos y fundaciones familiares en Al-Andalus (siglos IV/X-VI/XII), Madrid, CSIC, 2002. No entanto, a normativa portuguesa não permite tirar qualquer conclusão sobre este aspecto, com também é omissa na casuística das doações inter vivos relativamente a estes bens.

31. T.T., Chancelaria de D. Afonso V, Livro 34, fl. 12.

32. T.T., Chancelaria de D. Afonso V, Livro 16, fls. 138-139 v.

33. Ver M. ${ }^{\mathrm{a}} \mathrm{F}$. BArros, Tempos e Espaços de Mouros..., pp. 361-368. 
tariam sobre a alçada efectiva do respectivo imām e / ou de uma organização administrativa a ele subordinada. Neste sentido, excluir-se-ia a figura do alcaide, enquanto o máximo responsável da comuna, da gestão deste património, delineando-se uma demarcação entre o religioso e o secular, atípico das sociedades islâmicas, mas necessariamente interiorizado nas comunidades mudéjares peninsulares. De resto, esta perspectiva explicita-se no próprio discurso normativo produzido pelos muçulmanos sobre o direito sucessório, na denominação dada ao monarca português, como "o príncipe da terra" ${ }^{34}$, e na sua diferenciação com a figura do soberano em Terra de Mouros, onde ele se constituiria como "coisa piedosa"35.

Desta antinomia emerge uma outra categoria jurídica de apreensão sócioespacial, a dos bens de raiz comuns, gerais ou al-Musliminn ("dos muçulmanos"), que implicam uma titulatura do domínio da comunidade universal, ou umma, bem comum aberto ao uso e desfrute propriedade colectiva e indivisível do conjunto de todos os muçulmanos ${ }^{36}$. Este espaço comum, que sob domínio islâmico, não se subjectiva como bem de domínio público de um terceiro sujeito ou ente abstracto (o Estado ou a administração da cidade), mas como um domínio de uso e propriedade colectivos, próximo à noção de bens comunais, adquire, nas comunidades mudéjares portuguesas uma especificidade própria, no contexto particular de subordinação à sociedade cristã.

Deste modo, estes bens surgem numa zona exterior às mourarias, como património possuído ou de domínio útil, sendo perspectivado, pelo menos no que ao século XV se refere, menos como um espaço de usufruto colectivo, do que como uma área susceptível de rentabilização pela comunidade.

Diferentes referentes apontam neste sentido. Em Silves, é numa área contígua ao bairro, que se documenta um "ferregeal foreiro à mouraria", cujo domínio útil, em 1474, recaía sobre o tabelião Martim Pires ${ }^{37}$. Mais distantes da mouraria, se encontravam as propriedades da comuna de Elvas, num parcelamento pelo termo da vila que sugere, ao contrário do caso anterior, uma progressiva apreensão desses espaços. De facto, o próprio posicionamento do ferregeal da mouraria de Silves parece configurar uma rentabilização tardia do haram ou marfaq (espaço protector) do bairro ${ }^{38}$, numa expressão de domínio eminente

34. M. de Albuquerque (ed.), Ordenações Afonsinas, livro II, tit. XXVIII, p. 228.

35. Ibidem, p. 242.

36. J. García-Bellido y G. DE DieGO, «Principios y reglas morfogenéticas de la ciudad islâmica», Qurtuba, 2, 1997, p. 67.

37. M. J. LeAl (ed.), Livro do Almoxarifado de Silves (Século XV), Lisboa, Arquivo Nacional da Torre do Tombo, 1989, p. 32.

38. O haram ou marfaq, inserindo-se na norma de dominância dos bens colectivos, é constituído por uma faixa de terreno indefinida de propriedade comunal que circunda os poços, mesquita ou povoado, num conceito de criação de um espaço protector em torno de outro espaço, dependendo a sua escala e função do objecto de referência, J. GARCíA-BELLIDO y G. DE DIEGO, op. cit., pp. 68-69. 
da comuna muçulmana sobre esse património. Contrariamente, as propriedades de Elvas relevam de um contrato enfitêutico com o monarca, sendo aforadas "para todo o sempre ... a todos [os mouros forros] juntamente". Consistindo em herdades, vinhas e olivais, esses bens serão rentabilizados pela comuna, através de emprazamento aos próprios membros da comunidade ${ }^{39}$.

\section{O JUIZ DOS DIREITOS REAIS E O PATRIMÓNIO DO MONARCA}

A estes mecanismos de coesão social-espacial, uma outra situação se detecta na documentação compulsada que, se bem que apenas indirectamente relacionada com o direito islâmico, consagra, contudo, um exercício muçulmano de controlo sobre a propriedade. Situação excepcional que se regista apenas para Lisboa, no treslado de quatro diplomas (datados respectivamente de $1480^{40}$, de $1489^{41}$, de Março de $1491^{42}$ e de Maio do mesmo ano ${ }^{43}$ ) envolvendo a actuação do juiz dos direitos reais. Este verdadeiro magistrado "de fronteira", de nomeação régia e, por costume, sempre um muçulmano ${ }^{44}$, rege-se, contudo, pelo direito comum, no desempenho das suas competências, o julgamento, em primeira instância, de todos os pleitos relacionados com os direitos do monarca $^{45}$. Competências que, no entanto, em finais da centúria quatrocentista, extravasam as enunciadas por lei, envolvendo esse funcionário na própria gestão do património régio, como o testemunham os referidos diplomas.

Assim, os quatro casos remetem para cartas de aforamento na área de prolongamento do bairro muçulmano, o Arrebalde Novo, num acto presidido pelo referido magistrado, Adam Caroto (ou Caçoto), e assistido por outros dois funcionários, o procurador dos direitos reais (Azmede Caciz, nos dois primeiros diplomas e Mafamede Pintado, nos últimos) e pelo respectivo escrivão, desta feita o cristão Fernando Afonso. O processo, não apenas é presidido pelo juiz muçulmano, a quem compete, de resto, outorgar a respectiva carta contratual, como também decorre no espaço da minoria (na loja dos direitos

39. Embora não seja referida a data do aforamento inicial, ele será confirmado por D. Duarte em 1436, J. Alves Dias (ed.), Chancelarias Portuguesas. D. Duarte, Lisboa, Universidade Nova de Lisboa, 1998, vol. 1, tomo 2, doc. 1040, p. 311. Ver F. CORREIA, Elvas na Idade Média, dissertação de Mestrado apresentada à Universidade Nova de Lisboa, Lisboa, 1999, vol. II, pp. 583-584.

40. T.T., Livro 9 de Estremadura, fls. 45 v.-47.

41. T.T., Livro 9 de Estremadura, fls. 180 v.-182.

42. T.T., Chancelaria de D. Manuel I, livro 22, fls. 107 v.-108.

43. T.T., Chancelaria de D. Manuel, livro 11, fl. 80; publicado: S. VITERBO, op. cit., pp. 249-251. No entanto, este autor interpreta erroneamente o vocábulo como "acabal", assimilando-o a um outro, também de origem árabe, a alcavala.

44. T.T., Inquirições de D. Afonso III, livro 4, fl. 13 v.; publicado Portugalia Monumenta Historica. Leges et Consuetidinis, Lisboa, Real Academia da História, 1856, pp. 98-100.

45. M. de Albuquerque (ed.), Ordenações Afonsinas, livro II, tit. CI, pp. 534-535. 
reais e, no último caso, na zona onde se encontram essas propriedades, nas Olarias), num exercício de gestão do património régio exercido tanto sobre muçulmanos, como sobre cristãos. De facto, esses aforamentos são realizados respectivamente com o oleiro Rodrigo Afonso (por um pardieiro que fora tenda de olaria), com o fidalgo Pêro Lopes de Carvalhal (por dois chãos, a que haviam renunciado Iça Trocaleite e Mafamede Sobrinho), com Azmede Arangoês, e com Ale de Colares (em ambos os casos também por um chão), com a obrigação de valorizarem a propriedade, recuperando o património delapidado ou construindo novos edifícios.

A autoridade exercida por um muçulmano contradiz, de facto, a lei canónica tanto como a lei territorial, interditando os infiéis de exercerem qualquer poder sobre os cristãos. E algum poder era, de facto, exercido. Em nome do rei, sem dúvida, e numa espaço preferencialmente muçulmano. Mas não totalmente como, de resto, estes contratos o fazem supor e as confrontações das propriedades aforadas o confirmam ${ }^{46}$. $\mathrm{O}$ alargamento do bairro para norte, em direcção ao almocovar, no que constitui o chamado Arrebalde Novo da Mouraria, também designado como as Olarias ${ }^{47}$ ou sítio "onde estão os oleiros" ${ }^{48}$, revela-se, como outras zonas de ampliação do bairro ${ }^{49}$, uma área de população mista, de artífices cristãos e muçulmanos ${ }^{50}$. E não é apenas o juiz a exercer este tipo de autoridade. De facto, ele é coadjuvado por outro funcionário, o procurador dos direitos reais, também ele um muçulmano. Em dois dos diplomas, é referido expressamente que o contrato se celebrava por acordo entre ambos os oficiais ${ }^{51}$, revelando o papel activo do procurador no controlo e valorização do património régio. No caso do contrato com o oleiro Rodrigo Afonso, explicitam-se os procedimentos que lhe competiam neste processo: convocado pelo juiz, desloca-se juntamente com o escrivão para avaliar a propriedade e a pertinência da proposta feita. Apenas depois da sua avaliação ser comunicada ao magistrado, confirmando-se que

46. No contrato estabelecido com Rodrigo Afonso, o pardieiro, "que fora tenda de olaria", confrontava com uma tenda de Mafamede Agudo e com outra de Pêro Afonso - T.T., Livro 9 de Estremadura, fls. 45 v.-47; T.T., Livro 9 de Estremadura, fls. 45 v.-47; do terreno aforado a Ale de Colares, diz-se que limitava com o oleiro João Afonso e com Ale Becar - T.T., Chancelaria de D. Manuel I, livro 11, fl. 80.

47. T.T., Chancelaria de D. Manuel I, livro 11, fl. 80.

48. T.T., Chancelaria de D. Manuel I, livro 22, fl. 107 v.

49. Um arruamento que se começa a definir em finais do séc. XIV, num espaço a sul, imediatamente exterior ao bairro, a Rua de Benfica, constitui-se como outro núcleo de produção oleira com as mesmas características populacionais do Arrabalde Novo, ou seja, indiferentemente habitado por artesãos muçulmanos e cristãos, M. ${ }^{\mathrm{a} F}$. BARROS, «A Rua de Benfica da Mouraria (actual Rua do Benformoso) - sécs. XIV-XVI», Olisipo, II Série, 8, 1999, pp. 28-38.

50. A.H. DE OliveIra MARQUES, «A persistência do elemento muçulmano na História de Portugal após a 'Reconquista'. O exemplo da cidade de Lisboa», en Novos Ensaios de História Medieval Portuguesa, Lisboa, 1988, pp. 102-103; L.F. OliveIRA e M. VianA, op. cit., p. 199; Mª.F. BARROS, A Comuna Muçulmana de Lisboa (sécs. XIV e XV), Lisboa, Hugin, 1998, pp. 141-142.

51. T.T., Chancelaria de D. Manuel, livro 11, fl. 80; Idem, Livro 9 de Estremadura, fl. 181. 
era "serviço do dito Senhor", se procede à feitura do diploma ${ }^{52}$. Um outro oficial muçulmano é ainda referido num desses diplomas, o "recebedor dos direitos reais" (no caso Mafamede de Setúbal) ${ }^{53}$, a quem deveria corresponder o encargo sobre as receitas decorrentes destes contratos, como a designação do cargo o indica.

Ao juiz compete a autoridade superior sobre todo o processo. A ele "requerem" os futuros enfiteutas, a propriedade pretendida, é ele que "outorga" o pedido, estabelece as condições ("sob condição de") e, finalmente, "manda" ao escrivão fazer a respectiva carta e assentá-la no correspondente "livro do tombo". Mais problemática se revela a validação desses diplomas. Em 1498, é expressamente referido que o dito juiz assinou e selou o diploma, "com o sello das armas d'el Rey nosso Senhor". No treslado, refere-se que a carta parecia ser subscrita "de um signal mourisco", sem dúvida a assinatura em árabe de Adam Caroto ${ }^{54}$. No documento de $1480^{55}$ e no de Março de $1491^{56}$, menciona-se apenas o sinal do escrivão. Talvez a categoria social do enfiteuta do primeiro contrato, o fidalgo Pêro Lopes de Carvalhal, não seja estranha a uma intervenção mais solene do juiz, remetida, nas demais cartas, para a mera competência do escrivão.

A todo este processo se tem que juntar o seu carácter público e, concomitantemente, a acção deste magistrado muçulmanos perante as testemunhas muçulmanas e cristãs ${ }^{57}$. Mas ainda um outro factor se projecta, a partir destes diplomas, tão significativo como o próprio exercício de poder. O vocabulário delineia igualmente uma percepção muçulmana da propriedade aforada, que contrapõe, ao foro da terminologia cristã, o árabe tabal ou atabal $(t a b l)^{58}$. Assim, as propriedades são designadas como sendo de tabal, termo que assimila essa

52. T.T., Livro 9 de Estremadura, fl. 41.

53. T.T., Livro 9 de Estremadura, fls. 45 v.-47.

54. T.T., Livro 9 de Estremadura, fl. 181. As assinaturas e rubricas em árabe registam-se na documentação medieval portuguesa como um dos poucos testemunhos da adscrição a essa língua dos mudéjares do Reino; ver M. ${ }^{a}$ F. BARros, Tempos e Espaços de Mouros..., pp. 253-256; Idem, «Assinaturas árabes em documentos medievais portugueses» (no prelo).

55. T.T., Livro 9 de Estremadura, fl. 41.

56. T.T., Chancelaria de D. Manuel I, livro 22, fl. 108.

57. No diploma de 1480, Pêro Esteves, feitor de D. Pedro de Noronha (que, ao tempo, estava na posse dos direitos reais da mouraria de Lisboa, M. ${ }^{a}$ F. BARros, Tempos e Espaços de Mouros... p. 372), Gonçalo Eanes, porteiro da mouraria, Azmede Caciz e Mafamede de Setúbal, recebedor dos direitos reais; no diploma de Março de 1491, o procurador "mestre" Pintado (por Mafamede Pintado), Azmede Alcantarinho e o oleiro Rodrigo Afonso; João Afonso, oleiro, Gonçalo Eanes, porteiro da mouraria, Mafamede de Santarém "e outros", em Maio de 1491.

58. Assim, refere-se o pardieiro, "que era de taball", competindo ao enfiteuta cristão, o oleiro Rodrigo Afonso, pagar "de ataball" 52 rs. anuais (T.T., Livro 9 de Estremadura, fls. 45 v.-47); os dois muçulmanos, Iça Trocaleite e Mafamede Sobrinho, renunciaram aos "dois chãos de taball" emprazados a Pero Lopes de Carvalhal, que aceitou "pagar o tabal em que os mouros eram obrigados" (Idem, fls. 180 v.-182); Azmede Arangoês pagaria "de tabal" 52 reais (T.T., Chancelaria de D. Manuel I, livro 22, fls. 107 v.-108); finalmente, Ale de Colares emprazou um chão que "era de atabal", pagando o respectivo "atabal" de 36 rs. anuais (T.T., Chancelaria de D. Manuel, livro 11, fl. 80). 
mesma noção de foro ${ }^{59}$, e que parece impor-se apenas no contexto do mudejarismo português ${ }^{60}$, pese à sua utilização no período de dominação islâmica da Península Ibérica. A sua interpretação é, contudo, duvidosa, referindo-o LéviProvençal como uma contribuição censitária e Mikel Barceló como uma modalidade de dízimo ${ }^{61}$. Contudo, esta raiz é empregue coetaneamente pelos juristas do dār al-Islām, embora sob a forma verbal (tatbūl) "impor o pagamento do tabl) ${ }^{62}$ ou substantivada, na sua acepção de locação (taṭbil al-ardd, "aluguer da terra") ${ }^{63}$.

A enunciação árabe se, numa primeira fase, poderá denotar uma prática própria de locação de propriedade, acaba, no último quartel do séc. XV, por se identificar e traduzir a realidade do foro dos contratos enfitêuticos. Mas este tabal denota, ainda, uma afirmação da consciência da alteridade, quer em função dos parâmetros da comunidade, quer da respectiva hetero-percepção ("o tabal em que os mouros eram obrigados", como o refere o fidalgo Pêro Lopes de Carvalhal). Afirmação que, decorrendo da imanência do grupo, será ratificada pelo monarca e estender-se-á à população cristã que aí se fixa ou, de qualquer forma, detém propriedade.

Mais difícil será compreender, face à rarefacção documental, a extensão deste fenómeno, quer sob o ponto de vista cronológico, quer espacial. O carácter perpétuo e hereditário dos contratos parece caracterizar este processo, remetendo muito possivelmente para uma noção de direito próprio. De facto, os contratos enfitêuticos em três vidas, revelam-se como os mais comuns, ao longo dos sécs. XIV e XV, na mouraria de Lisboa, quer na relação contratual com o rei, quer com senhorios eclesiásticos. Talvez esse aspecto retenha uma das modalidades originais do conceito jurídico de tabal. A sua projecção para outros espaços da mouraria, para além do Arrabalde Novo, ou a latitude de intervenção do juiz dos direitos reais (que deveria acompanhar, de facto, a progressiva apreensão de propriedade por parte do rei nesse espaço ${ }^{64}$ ), são-nos totalmente desconhecidos. Poder-se-á, contudo, também especular, até que ponto o termo não envolveria uma percepção específica ligada à transformação

59. A sinonímia entre o tabal e o foro surge claramente plasmada no diploma de Pero Lopes de Carvalhal, o qual afirmou que queria "pagar o tabal em que os mouros eram obrigados", sendo-lhe aforada a propriedade, pelo juiz, com acordo do procurador, Azmede Caciz, com "seu encargo de foro asi como os dictos mouros pagavam" - T.T., Livro 9 de Estremadura, fl. 181.

60. Ele não surge, de facto, consignado nos tratados de direito islâmico em castelhano ou em catalão. De resto, também não é recolhido por F. MAílLo SALGADO no seu estudo, Los arabismos del castellano en la Baja Edad Media, $3^{\mathrm{a}}$ ed., Salamanca, Universidad de Salamanca, 1998.

61. Apud P. Guichard, Les Musulmans de Valence et la Reconquête (XIe-XIIe siècles), vol. II, Damas, 1991, p. 272.

62. Muhammad B. 'IYĀD, La actuación de los jueces en los procesos judiciales, tradução e estudo de D. SERRANO, Madrid, CSIC, 1998, p. 519 (glossário).

63. V. Lagardere, Histoire et Société en Occident Musulman au Moyen Âge. Analyse du Micyâr d'AlWanšarīsī, Madrid, Casa de Velázquez, 1995, n 194, p. 267; ver ainda n 259, p. 285 e nº 266, p. 287.

64. Ver sobre este aspecto: M. ${ }^{\mathrm{a}} \mathrm{F}$. BARros, Tempos e Espaços de Mouros..., pp. 465-474. 
do haram ou marfaq (espaço protector) do bairro, que, corresponderia à zona tardiamente urbanizada do Arrebalde Novo.

Como quer que seja, o vocábulo extingue-se, na medida do desaparecimento da minoria muçulmana, não parecendo deixar qualquer vestígio na língua portuguesa. No entanto, esse termo vinculou, pelo menos para a comunidade islâmica de Lisboa, a apreensão linguística de uma realidade económica, estruturada no modelo económico cristão, o da enfiteuse, e vivenciada em parâmetros comuns, mas traduzido em função do capital linguístico próprio e de uma autoridades muçulmana, exercida também sobre cristãos, porque delegada e sancionada pelo monarca português.

A um espaço globalmente dominado e controlado pela maioria cristã, contrapõem-se, pois, ainda no séc. XV, fórmulas de apreensão muçulmana, estruturadas pelo direito islâmico, fundamentando a solidariedade e a coesão sócio-espacial das comunidades mudéjares. Alguns destes aspectos (que este artigo não pretende esgotar) apenas muito esporádica e laconicamente assomam o acervo documental, consubstanciando, contudo, uma sociologia muçulmana assente no encontro entre os valores universais da 'umma e os particulares do seu contexto cultural de vivência. Vectores que, de resto, confluem no registo identitário próprio das comunidades mudéjares peninsulares, numa constante adaptação do direito islâmico ao pragmatismo de um quotidiano cristão, que também era o seu.

\section{RESUMEN}

El derecho islámico informa de la identidad de los musulmanes del reino portugués, desde el período matricial de su integración hasta finales del siglo XV. De la participación en los moldes de su propia subordinación fiscal y tributaria, a la cuestión del derecho sucesorio, los musulmanes legistas de Lisboa responden a las sucesivas interpelaciones de la Corona, constituyéndose el monarca como el principal beneficiario de esa producción legal. Esta manipulación del poder, el aspecto más visible en la documentación, muestra todo el dominio continuado de ese universo legal y de sus especialistas mudéjares. Aspecto que tendrá lógicamente su resonancia en la vivencia interna de estas comunidades, especialmente en lo que a la propiedad se refiere. El principio de la sunna de la dominación de los bienes colectivos se refleja en los bienes habices y los colectivos (al-Muslimina), aún documentados en el siglo XV. Por otro lado, la propia gestión del patrimonio del rey, en la morería de Lisboa, será dominada, en el mismo período, por una autoridad musulmana, el juez de los derechos reales, contradiciendo la ley canónica y la territorial que prohibía a los infieles ejercer poder sobre los cristianos. 


\begin{abstract}
Islamic law constitutes part of Portuguese Muslims' identity, since the formative period to the end of the $15^{\text {Th }}$ century. The Lisbon's Muslim jurists respond to successive appeals from the Crown, contributing as far as their own fiscal and tax subordination to the definition of succession rights. In any case the King became the main beneficiary of such legal production. This manipulation, the most visible feature in the written sources, proves nevertheless the persistent mastering of this legal universe and of its mudéjar experts, that will necessarily have its meaning in the daily life of the Muslim communities. Property reflects this feature. The dominance of collective goods, one of the sunna principles, projects itself in the hubs properties and in the collective goods (al-Muslimin), acknowledged till the $15^{\text {th }}$ century. Moreover, the actual management of the King's properties in the Muslim quarter of Lisbon, in the end of the same century, was in the hands of a Muslim authority, the judge of the King's rights, contradicting the canonical and the territorial law that prohibited the infidels to exercise power over Christians.
\end{abstract}

